\title{
A Study on the Role of Higher Education in the Development of Society
}

\author{
*Dr. Ashalatha K \\ **Nandini Shetty \\ ***Ratul Kamath \\ $* * * *$ Nishita Shetty \\ ****Rakshath
}

\subsection{INTRODUCTION ON HIGHER EDUCATION}

The global meaning of tertiary education divides it into two sections. Type one is Higher Education and the other is Further Education. An advanced education capability at degree level takes at least three years to finish, even more ordinarily four. Advanced education mainly and generally means university level education. It offers various capabilities going from Higher National Diplomas and Foundation Degrees to Honours Degrees and as the further step, Postgraduate projects, for example, Master Degrees and Doctorates. These are recognized everywhere throughout the world as representing to proficient aptitude supported by a wide variety of abilities that businesses find extremely advantageous. Further education is, for the most part, incorporates those postgraduate examinations in where you can pick up your Master and Doctorate degrees.

Usually the degrees divided into two levels. These degrees are helped to earn huge. Master's degree has more scope and significance when compared to baccalaureate degree. This master's degree has several streams such as Master of Science, Master of Arts, Master of Commerce and Master of Theology. The time taken to earn master's degree depends upon the programs the people enrol themselves may be fully fledged program or distant education, or correspondent education. The usual program takes at least 2 years to complete. The other kind graduate degree is a doctoral degree which is considered higher than a master's degree. Doctoral degrees are professional in nature such as Doctor of Philosophy, Doctor of ministry, etc. The time taken to complete degree varies based on the field chosen. Once they are successful in achieving, they are eligible for the tittle "Doctor".

\subsection{PPP model in Education}

PPP is a trending word in Educational sector. It can be defined as a contractual relationship between government and private sector for particular project. Under PPP model the public sector joins hand with private sector for business relationship. Present education is generally recognized as the responsibility of the government. At present government is spending nearly 1\% GDP in education and it tries to increase GDP to $1.5 \%$ in future. 
Recently, the UGC has suggested 4 PPP model to the planning commission and to implement this model country requires $\$ 150$ billion in next 10 year. The first model tells that the private sector invests in infrastructure and government runs and operates in turn it pays to the private investors. In the second model, the private sectors not only invest in infrastructure but also manage the institutions and government pay for selective services which will aid from the institution. Third model of PPP tells that investment is done from both government and private sectors but run and managed by private sectors. Where as in the 4th model the investment is done by government and private sector helps in run and managing the institution.

In case of Education, they initiated this PPP model as key strategy in the Eleventh Five Year Plan under this plan 6000 new model schools in secondary education, afflicted to CBSE out of there 2500 schools are under the control of PPP. The main Moto is to establishing the schools in such an area where good school facilities are not are not available and to develop the wealth backward region and to improve their quality life.

\subsection{Gandhiji's view on Education}

\subsubsection{Social, moral and economic progress of a} country ultimately depends on Education:

Gandhiji stated that progress of a country of a country depends on education. The factors that contribute to the progress are Social, moral and economic. People should be well educated in order to socialise with people. Behaviour, discipline and respecting others everything depends on education that we have been taught, without proper education a person won't get much respect in the society because of bad behaviour towards others. Morally a person should be good; a person's character should be good which can be built by education. In Gandhi's opinion character building is the most important among students. Economic progress too contributes towards progress of a country. A person should have basic knowledge about country's economic factors i.e. Natural resources, Infrastructure, Population, Human capital, Technology and law. A person should be educated on economic factors of a country so that he will contribute towards it and take a step forward to progression of a country 1.3.2.Highest aim of education is the Self -Realization:

In Gandhiji's opinion the highest aim of education is Self-Realization. Gandhiji used to say that "The end of all knowledge must be building up of character". A person should realise the value of education by himself; it should not happen that a person is being forced to pursue his education. He should know the importance of education; what education can do to him and to the society, what are the things that can be achieved through education. The purpose of education can be achieved only if a person realises the value of education. 


\subsubsection{Basic Education is Education for life and}

\section{through life}

Basic Education is for life and through life. Education should never stop for a person. Everyday should be a new learning for a person. Just because a person has completed his higher education doesn't mean his learning has to stop or his education should be stopped. A person's education should keep on going every day; no person is master in anything. Every person including great scientist learn and educate themselves every day.

\subsubsection{Higher education should be made self- supporting}

In Gandhiji's views higher education is made selfsupporting. He gave special importance on the training of Hand, Heart and Head. Gandhiji said, "Physical Exercise, handicrafts are necessary in a school. Education helps in cultivation of absolute Purity of heart. He related every student as a Brahamchari. Every student is lone wolf in a corporate world, if a student has to succeed then there should be self-supporting within him where education will act as a great tool for a student.

\subsubsection{He laid more stress on environment than}

\section{books}

Every student should focus on environment than books. There are many under developed abilities in the environment which will be of great help for the students in terms of education. Gandhiji tells that the student should not only read the theories that are there in the book but also should have exposure of environment which has a connection to education. Students should know the actual work; how and where to apply the studied theories. He stressed on importance of manual skills where students should participate in the work done in school. He felt work and play are important for education.

\subsubsection{Teachers should motivate the students}

Gandhiji told that the role of teachers is to motivate the students. Students should be curious enough to know, what's happening around them. Teachers should motivate the students in all possible manners. Teachers should encourage as if every day is a new learning. Linking it to the management view students should follow Theory Y and not Theory X.

\subsubsection{Helaid focus on co-education in schools}

He didn't want to differentiate between boys and girls. He focused on co-education in schools. For Gandhiji boys and girls where same when it's about education, both the gender should study together.

\subsection{Gandhiji's concepts of Education}

Gandhiji's concepts of Education are known as

Basic Education, which aims the following:

\section{Formation of good character}

2. To be ideal citizen

3. To have democratic ideals

4. Self-Reliance

5. All round development

6. Complete Development

7. Character formation 


\subsubsection{Concept of Basic Higher Education}

The concept of basic education in India was raised by Mahatma Gandhi to make school education self-reliant. All the primary and upper primary schools are supposed to give lectures and small group activities to the children; the output from the teaching would be meeting the salaries of staff. After which all primary and upper primary schools were then converted as junior and senior basic schools in India. On the other hand, the international community defines basic education as"The whole range of educational activities that take place in different settings and that aim to meet basic learning needs".

\subsubsection{Relevance of Basic Higher Education to Society}

\subsubsection{Propagation of knowledge}

Transfer of knowledge from one generation to another or from one country to another other country is possible through education. Knowledge of current generation will be shared with future generation. For example: History and science (Newton's law). Without education transfer of knowledge cannot be done.

\subsubsection{Improvement of technology}

Improvements in medicine, war equipment, technology were possible due to constant exploration and research. All these improvements contribute to the society; Improvement in medicine will lead to good health and will live a long life. Improvement in war equipment will save people plus there will be no war because of fear that the enemies carry. Technology advancement will make a society a better place to live; all work can be easily done easily because of improvement in technology. All these improvement can be done through one medium that is education.

\subsubsection{Better Social harmony}

Education leads to better social harmony because different cultures, religions, sectors come as one and study together in schools and colleges. Thus it will help them to understand each other better and stay in mutual harmony.

\subsubsection{Illiteracy breeds Illiteracy}

If the current generation are illiterates then the future generation will also be illiterates. Illiteracy breeds illiteracy. Parents who are not educated won't support their kids for education instead will ask them to work. On the other hand parents who are educated will educate their children's for higher education. If the current generation doesn't know the value of higher education then the legacy will keep on continuing. Hence education will lead to breeding of only literates and making the society a better place.

\subsubsection{Development of Society}

Education will lead to development of society; its factors being social, economic and infrastructure development. If people are educated then they will be employed then they won't have any fear of adapting towards new infrastructure facilities and other factors. They will have an intention of development and having high levels of per capita income which will lead to better living standards and quality of life. 
An uneducated society on the other hand will be underdeveloped and its per capita income will be extremely low, which affects their living conditions and hence will have poor quality of life. The average income earned by the individuals will be low due to their low productivity because of their illiteracy.

\subsubsection{Better Law and Order}

Education will lead to better law and order. People who are educated will know the importance of law and order; why they are made and how it should be followed. If people are educated then they won't break any rules and laws which will be of good sign to the society. People won't do crimes, frauds and thefts.

If people aren't educated then they tend to break the rules because they won't know the importance of law and order. If people are not educated then they will have to be dependent on someone's hard work. People then do some crimes and frauds to loot other people in order to meet his and his family's daily requirements of food and money. It doesn't mean that all uneducated people are criminals; nearly $70 \%$ of the criminals are uneducated.

\subsubsection{Wealth and Abundance}

If the society is educated then the society will be wealthy in terms of social and financial needs of its members. If the members of the society are employed in the business or in a profession then the members will be wealthy enough to sustain their needs; living a happy and prosperous life.
They will access towards the resources and are skilled enough to use them for their financial and social development. The society members understand that only educated society can make them stay together and will have an abundance of opportunities, facilities and amenities.

\subsubsection{High Self Esteem}

Self-esteem of an individual depends on how that individual looks after his or her family, what they contribute to the society, their social status, standard of living and various other factors that are similar. Hence it can be said that a literate society is a group of people with high self-esteem and will have access to good facilities and better living environment.

\subsubsection{Gender Equality}

An educated society will not discriminate between genders and will provide equal opportunities to both the genders. Women are employedin an educated society, meeting their family needs and improving their financial and social status. An educated society understands the need to be gender neutral and its significance in social and economic development.

\subsubsection{Health and Hygiene}

An educated society will live in a healthy and hygienic way than an illiterate society. An educated individual knows the threats to their lives that will cause to them if they live in unhealthy and unhygienic way. Education is a tool that an individual uses to analyse, understand and then finally tackle the threats that will cause to them 
and their families. They have knowledge about medical advancements which can cure them if they sick.

\subsubsection{Better Political State}

A literate society will have better political state as they understand what's good and bad for them and also for the nation's betterment. Educated individuals are more likely to take wise while choosing their political representatives. They know who is making fake promises and who follows the promise that they do. An educated individual will not get carried away by someone's false speech that they give.

\subsection{Implication of Basic Higher Education to Society}

\subsubsection{Science and technology}

Education teaches us science and technology which can be used for the society for a better living. Through science we can create wonders in the world and through technology we can make our work easier and will have access to everything which was never seen before. We are living in a world full of science and technology. In everything there will be science or technology. There is nothing in this which world science can't do. Science has proven everything. It is because of the education that science has reached upto a level, scientist educates others and then the students will experiment and will create wonders after a year of hard work. Science is not easy as it seems to be, it requires years of hard work and education about everything which can do something good to the society. Technological advancement is another thing which can be done achieved education. An individual must be well educated for a technology to be improved. Innovative technology is in high demand these days and it can be achieved through education what an individual studies. Technical Education can meet the increasing demands of increasing society and it's multiplying demands and development.

In our day to day life the influence of science and technology is becoming so effective that human existence is simply unthinkable in its absence. This is the reason why we must train our students/professionals in response to the need of the time; our education system must be reorganized and must give the necessary practical and technical bias knowledge.

\subsubsection{Human development and economic growth}

The education impacts on human development and economic growth. The education assists the human values which contribute to everyone. Education is undoubtedly one of the most important factors that will help our countries growth and development of our country as well. The increasing population in our country can bring much development in the future.

The Kothary commission says that, "No nation can leave its security only to the police and the army, to a large extent national security depends upon the education of citizens, their knowledge of affairs, their character and sense of discipline and 
their ability to participate effectively in security measure.'

The main problem of our country is our country fails to retain the brains. Our country engineers have a great demand in the developed countries. The intelligent brains from many colleges are being evacuated from India. Some people feel job facilities are good not good in India but are good in foreign countries. Foreign countries pay very high amount of salary to talented youth minds. The government of India should try to change this proportion. We should avoid this brain being evacuated and try to use the ideas to our country itself. This will help our country to become number one nation in the world.

\subsubsection{Promoting sustainability}

Educates promotes sustainability i.e. the education must sustain and not be washed out from our country. Everyone is being encouraged for education which will contribute towards society. The Illiteracy rate will fall down and our country will become a literate nation. Educated individual will know the importance of education so he will make sure that education will sustain and not vanished. Education must be sustained for country's growth and development which can be done only through an educated individual where he will influence others

\subsection{Higher education influence on society}

In today's era of VUCA wold the knowledge is very important. Today's knowledge driven and learning based societies the higher education creates important role in human life. The formal or informal higher education is playing a vital role in devolvement of society, people, future needs, promoting economic solidarity, and individual growth, sustainable developmental and good citizenship with culture of peace. The higher education is a contributor of knowledge future generation with more responsibility. The higher education influence like it create challenges and opportunity with in the society.

\subsubsection{Higher education is a production and development of qualified human resources.}

The mainly higher education influence in society like create qualified knowledge human resources. The competitive wold the knowledge take lead role. The higher education facilitates and create the qualified human resources. In the view of higher education as process in labour market higher education produce the qualified product to competitive oriented labour market and becomes inputs to the sustainable growth with development of corporates and business.

\subsubsection{Higher education as preparing for a research career.}

The student get in to higher education, this process creates students like research oriented minds. The higher education is the preparation of futures qualified scientists, subject specialist and researchers. Those peoples develop the knowledge and quality to concentrate on more research and publication. 


\subsubsection{Higher Education as the efficient in creates management skill.}

Import of knowledge in higher education is forms a knowledge orient people and focuses on management skill. The higher education efficient in teaching in particular specialised in particular one subject and creates specialist in it, with learning the efficient management skill among the student.

\subsubsection{Higher education as a subject of extending life-chances and growth.}

Some research on higher education says doing higher education creating more job opportunity and easy to get the job. The higher education is an opportunity to participate in development process in individual person with creates new opportunity in life for growth.

\subsubsection{Contributing to national development}

The higher education gives a marvellous benefits to society towards national development. The higher education and growth in between to there is positive relationship. The higher education creates knowledge citizens it helps in growth of individuals. In total the growth of per individuals helps in growth of entire society. The high skill people is an assets of the nationals. When the individuals get higher education creates positive mind-set among them it helps to give analytical thinking it benefits the sustainable growth in economy and he thinks towards nations.

\subsubsection{Quest for excellence}

While contributing to nation building and development the higher education take lied role, and higher education institution also concentrate towards excellence. Highly educated people are a back bone of the economy and society. The outstanding quality of higher education results in the quality of human resources in the society. At present, higher education is considered to be a very complex system which resources to growth, teaching, international collaboration along with mutual understanding and also the research in various aspects.

\subsubsection{Promoting the use of technology}

In current situations the colleges and universities has promoting technologies and also quick to adopt new technologies. In this higher education has experimented with technology advances and implemented on society. Educational institutions to more concentrate on value add creation of education like finding new technological advance on society and implemented on society.

\subsubsection{Fostering global competencies among students}

The higher education facilitated the student to face the global competencies. The higher educational institutions gives value and skill based training to explore in the global market. The higher education creates man power resources in rapidly changing world. 


\subsubsection{Inculcating a value system in student}

In higher education system the student learn the value based curriculum and designing special orientation programmes helps to inculcating a value in a student. The increasing value in the future generation it helps the overall growth of society. The higher education also increases the level of code of conduct and philosophical view towards life.

\subsection{Higher education connect to society}

\subsubsection{Spreads Awareness}

The education helps us in understanding the difference between the right and wrong. The education teaches us how to find the scientific reason behind everything. It is something which makes us ask question. Education makes a person aware about his/her nation, language, culture, history, science etc.

\subsubsection{Build \& Develop Women within the system}

The education makes everyone read and know about equality, it makes sure everyone understands the value of each gender. The trend of women empowerment is increasing and the number of women enrolling for higher education is increasing. As women play a vital role in improving and building the family, nation and society. Thus it is really important if both male and female gets educated.

\subsubsection{Entrepreneurship development}

The higher education makes the people know about entrepreneurship and make them become entrepreneur. Education institution helps know more about different subjects and help the student take up entrepreneurship. The student will be able to learn theories and will be able to apply it in real situations in the future.

\subsubsection{Envisioning a Sustainable Future}

Education helps in changing the mind-set to achieve long term effort to completely transform growth at all levels. It creates a sustainable future in today's world. Education also makes people understand moral values and the leaders understand moral responsibility. By increasing the knowledge, skills and knowledge it is possible to build a better generation for the future. Higher education will help in achieving this.

\subsubsection{Education and economic growth}

\section{relationship}

The purpose of the economic activities that people place fourth in social life is to fulfil to their basic desires. Whereas fulfil the fundamental desires, it's necessary to struggle with the constraints encountered. Gazing the economy as an entire, it's geared toward increasing and maintaining the prosperity levels of the social area unit a basic policy. Nowadays, whereas the strength of arm power is greatly reduced in production, the role of brain power and machines is increasing. This structural modification in production, whereas reducing the physical role of individuals within the production method, offers individuals longer 
for activities. This will solely be achieved by creating mandatory investments for human capital. The rising human capital helps to development of the economy. Education plays an essential role in developing the human resources which is the key to technological and scientific progress. Moreover, education is seen as a path to economic well-being and is considered to be of most important to bring change in the state, make certain solid foundations, to bring social equality, awareness and cultural vitality.

\subsection{LITERATURE REVIEW}

-Dr. Satyabrata Mishra in the paper "Role of Education in Growth and Development of the Society" published in the Splint International Journal of Professionals on July 2016 tell that the general presumption at the susceptible or negligible role of secondary and better schooling in development isn't always valid and that put up-primary education performs a sizeable position in improvement. Post-Primary education results in economic increase. After all, while primary training offers the basic 3 r's and critical and vital for improvement, but now not ok for overall sustainable development. Most of the literacy and primary training Programme are also observed to be no longer providing literacy that is sustainable, in order that children do not relapse in to illiteracy. Even if number one education imparts a few precious attributes, in terms of attitudes and abilities and if number one education is capable of taking the humans from below the poverty line to above the poverty line, it's possible that this may be just above the poverty line. It is secondary and Higher education which can maintain the human beings above poverty line without this kind of threat of falling back into poverty trap educational poverty or profits poverty and actually it's Secondary and Higher education which can take humans to above the poverty line by using increasing the social, occupational and economic level of the families. Further, it is Higher education which could make sure sustainable economic growth, as it is Higher education or the specialized human capital that allows people and international locations to resist economic shocks, face disequilibria and to be able to restore equilibrium. This is Secondary and higher training that forms a human capability and human freedom that enables in attaining different freedoms.

- Nicea Mergeani in the paper "Linking Higher Education With The LabourMarket, Unemployment Reduction Target AmongYoung Graduates Of Higher Education" published in the 15th International Scientific Conference on Economic and Social Development on June 2016 tell - one that doesn't provide too many perspectives to current and future graduates of better education, because the training system has not been adapted to the needs of the labour marketplace inside the last many years. Young individuals who do not have a relaxed process are hopeless, are skeptical and introvert and are thinking about leaving to United States as quickly as they finish excessive college or when they turn 18 or are thinking about starting 
their very own commercial enterprise. But there are additionally younger people who need the entirety without supplying whatever but they input some other category. Society desires mindblowing variations at the instructional stage. Besides the reality that universities ought to renew their strategies and be greater cautious when choosing managers, it is also necessary to stimulate the younger human beings via powerful programmes of research. Of path, the kingdom has a critical position in these changes, and the granting of aids to that effect could be more than useful. At the same time, universities need to draw up wonderful contracts with large corporations to put together college students for the desired fields. Encouraging volunteerism and undertaking actual sensible education must now not be unnoticed, even though. Also, allow us to not lose sight of the idea that training plays a prime function in creating human capital, therebycontributing to the economic increase and growth of manufacturing just like human capital. Analysis of the consequences generated by means of government policies within the discipline of training on financial increase represents a topic deserving of unique attention, given the fantastic impact of the growth in training spending on the financial boom.

- Sandy Baum and Kathleen Payea in the paper "The Benefits of Higher Education for Individuals and Society" published in the Education Pays on 2004 tells that Students who attend institutions of higher education acquire a wide variety of private, financial, and other lifelong advantages; likewise, taxpayers and society as an entire derive a mess of direct and indirect benefits when residents have to get right of entry to postsecondary training. Accordingly, uneven fees of participation in higher training throughout different segments of U.S. Society ought to be a count number of pressing interests no longer most effective to the individuals without delay affected, however also like a count number of the public policy at the federal, state, and local levels.The number of higher education's advantages to society, gaps in getting admission to the university are subjects of superb significance to us of as a whole. This document suggests that despite the progress we have made in improving educational possibilities, participation in higher training differs notably with the aid of a circle of family income, parent education level, and different demographic

\subsection{CONCLUSION}

Higher Education is the foundation for a vibrant democracy in which all knowledgeable residents' workout their franchise to guide the internal boom of the nation, its positive function within the world community. It is the muse for boom in productiveness, incomes and employment possibilities, and for the development, utility and variation of sciences and technology to enhance the fine of existence. Higher Education is hence the foundation for the access to the advantages of the records revolution that could open up vistas to the entire global. 


\section{REFERENCES}

http://www.indianetzone.com/38/history higher education india.htm

Central Advisory Board of Education, 2005

http://www.isb.edu/.

http://www.symbiosis.ac.in/

http://wwydl.iglereducationinindia.com/

Accessed on: August 07, 2011

www.academia.edu 